\title{
Kim J. Burchial: Handbook of pain surgery
}

Thieme Verlag, New York, Stuttgart, Delhi, Rio de Janeiro, 2017, 400 pp, 132 figs., $127.0 \times 203.0$ mm, Hardcover, EUR (D) 74,99 EUR (A) 77,10 CHF 86,00, ISBN: 978-1-62623-871-8

\author{
Alain G. Graftiaux ${ }^{1} \cdot$ Pierre Kehr $^{1}$
}

Received: 6 April 2018 / Accepted: 20 May 2018 / Published online: 4 June 2018

c) Springer-Verlag France SAS, part of Springer Nature 2018

This book takes stock of a surgery a little except for, badly known of the orthopedic surgeons. The description of the surgery of the pain in the books is rare.

After a first chapter on the medical care, the other chapters describe the various techniques and surgical procedures: central and peripheral stimulations, therapies intra-thecal, denervations and cordotomies...

A chapter except for draft of the pains cervico-facial.

Videos which accompany this book are available on the website of Thieme and supplement this book usefully.
Initially a little difficult, this book makes it possible nevertheless for the interested surgeons to have a precise idea of the actual position of these treatments. This will make it possible to consider other treatments in the rebellious pains for which we are sometimes confronted and often stripped.

\section{Compliance with ethical standards}

Conflict of interest The author(s) declare that they have no competing interests.
Pierre Kehr

Strasbourg, France 